\title{
Philips Lifeline CareSage Analytics Engine: Retrospective Evaluation on Patients of Partners Healthcare at Home
}

Mariana Simons ${ }^{1}$, MSc, PhD; Jorn op den Buijs ${ }^{1 *}$, MSc, PhD; Linda Schertzer ${ }^{2 *}$, BSc

\footnotetext{
${ }^{1}$ Philips Research, Eindhoven, Netherlands

${ }^{2}$ Philips Lifeline, Framingham, MA, United States

*these authors contributed equally
}

\section{Corresponding Author:}

Mariana Simons, MSc, PhD

Philips Research

High Tech Campus 34

Eindhoven, $5656 \mathrm{AE}$

Netherlands

Phone: 31613503396

Fax: 31613503396

Email: mariana.simons@philips.com

\begin{abstract}
Background: The most common cause of emergency transports/admissions in the aging population is deterioration in their health status due to multiple chronic conditions. To meet the needs of this population, healthcare systems are seeking cost-effective ways to monitor, diagnose, and treat patients, based on connected solutions that seamlessly integrate data and provide actionable insights. The Philips Lifeline's CareSage program for elderly and frail people utilizes a Personal Emergency Response Service (PERS) to detect medical emergencies and to promote independent living. The system tracks the types and outcomes of incidents, in particular the emergency transport-related events. Their timely detection is critical in optimizing clinical and financial outcomes.

Objective: The study objectives are to evaluate (1) healthcare utilization and expenditure and (2) the CareSage predictive model on patients of Partners Healthcare at Home who have been using the Philips Lifeline service. This study is unique in utilizing PERS connected technology as a source of data to identify patients at risk of emergency transports or admissions that cause high healthcare expenditure.
\end{abstract}

Methods: We identified 3335 patients with in-/out-patient encounters in 5 Partners Healthcare-affiliated hospitals through cross-reference of Philips Lifeline and Partners Healthcare at Home (PLL/PHH) data. The patients' demographics, clinical outcomes, and healthcare expenditure for fiscal years 2011-2015 were extracted from Enterprise Data Warehouse (EDW) of Partners Healthcare. The medical alert data related to PERS utilization were extracted from the Philips Lifeline database. Retrospective statistical analysis of hospital utilization and healthcare cost was performed. Further, the CareSage logistic regression model that uses only PERS data to predict emergency room (ER) transport was validated on PHH patients. A new model predicting ER admissions was developed using boosted regression trees on a combination of PERS and electronic health record (EHR) data. Model performance was evaluated by the area under the receiver operator characteristic curve (AUC) and the positive predictive value (PPV).

Results: Patients in the top (5\%), middle (6-50\%), and bottom (51-100\%) segments of the cost acuity pyramid account for $40 \%$, $55 \%$, and 5\% of the total healthcare expenditure, respectively, and these percentages stay stable across fiscal years 2011-2015. Increasing trends in total cost and average cost per patient and per encounter were detected through 2011-2015 based on linear regression analysis. The current CareSage predictive model that identifies patients at high risk of emergency transport in the coming 30 days has $\mathrm{AUC}=0.74$ on the $\mathrm{PHH}$ population, whilst the new model that identifies patients at high risk of emergency admission in the coming 30 days has AUC $=0.82$. For prediction windows of one year, the PPV in the top 5\% was also good: $63 \%$ and $67 \%$ for emergency transport and admission, respectively.

Conclusions: Predictive models based on PERS and EHR data can identify patients at risk of emergency transports and admissions that account for high healthcare cost. Healthcare organizations can use the outcome of the predictive models to design relevant interventions targeting their high risk patients. 
(iproc 2016;2(1):e8) doi: 10.2196/iproc.6105

\section{KEYWORDS}

data analytics; predictive modeling; healthcare utilization; healthcare expenditure

This poster was presented at the Connected Health Symposium is displayed as an image in Figure 1 and as a PDF in Multimedia 2016, October 20-21, Boston, MA, United States. The poster Appendix 1.

Figure 1. Poster.

\section{Philips Lifeline CareSage Analytics Engine Retrospective Evaluation on Patients of Partners Healthcare at Home

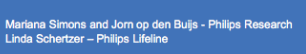
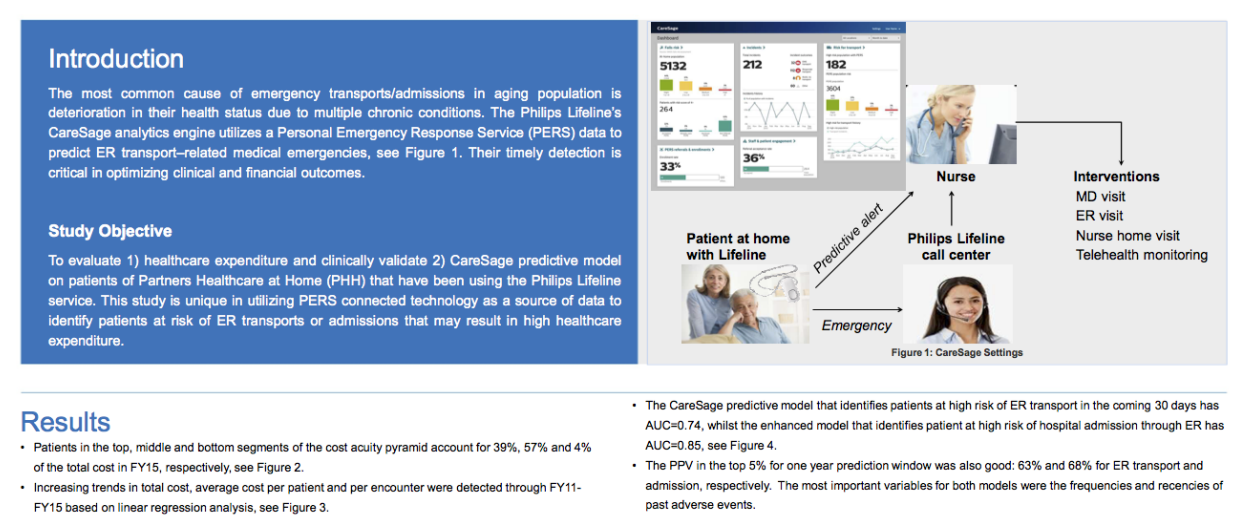
The Caresage predictive model Ihatidentifies patients at high risk of $E R$ transport in the coming 30 days has
AUC=0.74, whilst the enhanced model that identfies patient tat high risk of hospital admission through $E R$ has AUC $=0.85$, see Figure 4 .

- of the total cost in FY15, respecively, see Figure 2 .
FYcreasing trends in total cost, average cost per patient an
Fysed on IInear regression analyss, see Figure 3 .
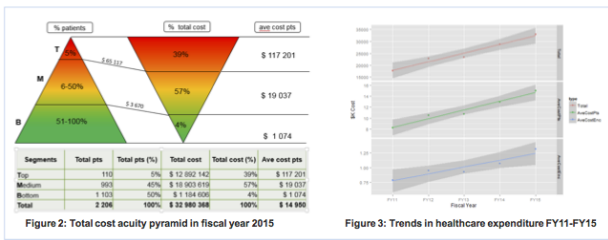

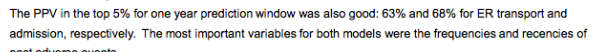

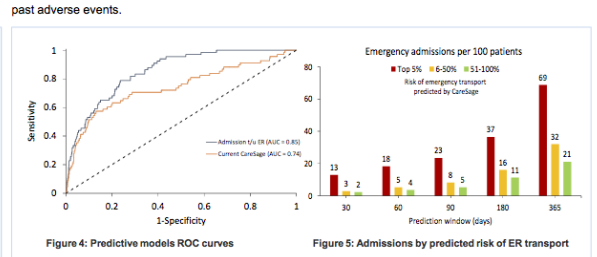

\section{Multimedia Appendix 1}

Poster.

[PDF File (Adobe PDF File), 415KB-Multimedia Appendix 1]

Edited by T Hale; submitted 03.06.16; peer-reviewed by CHS Scientific Program Committee; comments to author 22.08.16; revised
version received 29.08.16; accepted 29.08.16; published 12.12.16
Please cite as:
Simons M, op den Buijs J, Schertzer L
Philips Lifeline CareSage Analytics Engine: Retrospective Evaluation on Patients of Partners Healthcare at Home
iproc $2016 ; 2(1):$ :e8
URL: $\underline{\text { http://www.iproc.org/2016/1/e8/ }}$
doi: $10.2196 /$ iproc.6105
PMID:


CMariana Simons, Jorn op den Buijs, Linda Schertzer. Originally published in Iproceedings (http://www.iproc.org), 12.12.2016. This is an open-access article distributed under the terms of the Creative Commons Attribution License (http://creativecommons.org/licenses/by/2.0/), which permits unrestricted use, distribution, and reproduction in any medium, provided the original work, first published in Iproceedings, is properly cited. The complete bibliographic information, a link to the original publication on http://www.iproc.org/, as well as this copyright and license information must be included. 